\title{
High Frequency Antenna Design Challenges for Underwater Communication - An Intensive Probe
}

\author{
Basim Basheer, Nebu Pulickal and Suriyakala CD* \\ School of Ocean Engineering \& Underwater Technology, India
}

Submission:December 02, 2017; Published: January 22, 2018

*Corresponding author: Suriyakala CD, Director, School of Ocean Engineering \& Underwater Technology, KUFOS, Panangad, Kochi, India, Email: drcdsk@yahoo.in

\begin{abstract}
Underwater sensor nodes enable applications for marine data collection, pollution monitoring, offshore exploration and tactical surveillance applications. These sensors which are placed on underwater vehicles are also used in the exploration of undersea resources and gathering scientific data in collaborative monitoring missions. To make these applications possible, communications must made be made possible underwater devices. These networks consists of a number of sensor nodes and vehicles that are deployed to perform collaborative monitoring tasks over a given area.
\end{abstract}

In this paper the detailed survey study of several techniques related to underwater communication antenna systems and challenges for establishing a communication network which are posed in the deepwater bed and the possible solutions for overcoming the issues are discussed.

Keywords: Underwater communication; Sensor network; Acoustic communication; Oceanographic communication challenges

\section{Introduction}

The advancements in technology and innovation have been mainly focusing towards the wireless and terrestrial communications. The challenges and scope to explore the possibilities of further advancements in underwater communication remains a non-trifling issue. Most of the research and developments have been mainly focusing on improving the existing and booming commercial application sector. The vast ocean of opportunities still remains unwatched beneath [1-3].

An index to showcase the growth of a nation is the deep exploration and classification of the water bodies. Several applications may include traffic control of vessels, dredging operation, fisheries research, under water environmental studies, weather estimation ocean characteristic study, deep ocean communication etc.

\section{Discussion}

Underwater communications have been limited in distance due the high attenuation at acoustic frequencies. Frequency range used in acoustic communication for obtaining high range with lower resolution capability is between the $10 \mathrm{KHz}$ and $1 \mathrm{MHz}$. Studies have shown that an intermediate range can serve good resolution and range capabilities. Synthetic aperture SONARS on intermediate frequency with better optimized designs may be used for high resolution data capture.
Previous researches have been focused in channel characterization and not in antenna design which influences its structural parameters as well as the changes in different environmental conditions. The great difference in designing an antenna when the propagation medium is water, is the change of the medium's density which limits our frequency options $[4,5]$.

Underwater wireless systems require highly efficient underwater antennas to realize high data rate communication. Since most underwater environments are lossy mediums affecting the characteristics of conventional antennas, an antenna -wide band circular microstrip patch antenna design for $500 \mathrm{MHz}$ was considered contained by a buffer-layer is considered.

Underwater communications are used in numerous applications like environmental monitoring, offshore gas or petrol extraction, renewable energy plants and undersea infrastructure maintenance. Most of those application sites are distant and inaccessible to the end users of telemetering systems or remote controlled devices. In monitoring of water quality uses a network of stand-alone low power sensors located under the water surface. For deployment ease, such a system requires wireless communication to upload the measurement data to a data collection base situated at a remote location [6]. 
Wearable acoustic model sensors were being used for human body analysis of electrocardiogram and electromyogram signals. Magnetic induction has been proved as an efficient solution to achieve reliable communication in environment where wireless communication has many constraints.

Acoustic metamaterial design gave rise to the opportunity to design and develop an artificial media with negative refractive index whose application was focused on super-resolution imaging. These high resolution acoustic imaging techniques are the essential tools for medical screening and non destructive testing. Another concept shows work in the area of water based meta materials. In this porous rubber micro-beads suspended in a gel was found to exhibit negative acoustic index of refraction which makes them promising for under water applications with great benefit to the society [7].

Wearable or body implantable type of antennas has gathered interest in research due to its conformal design aspects and capability to embed sonar and other sensors for data acquisition. The major challenges facing for wearable structures for underwater communication are the need for small, light weight and power efficient models. This area has major application in the wireless transmission of underwater diver's data. While designing the underwater antenna structure we need to consider various constraints in underwater like salinity, high attenuation, variation in density, pressure for shallow and deep sea water, turbidity, thermal variations etc. Magnetic induction has been proved as an efficient solution to achieve reliable communication in underwater environment where conventional wireless communication is facing too many constraints. For enhancing magnetic induction metamaterial structure will be tried to study the key performance of antenna compared to the wearable antennas in free space communication medium.

\section{Conclusion}

There is very little literature published about EM waves because this technology is not much used in underwater communications. There is not too much documentation about high frequency in underwater communications because most of the works are designed for low frequencies in order to achieve large communication distances, preventing the power losses generated in high frequencies.

Vast survey shows the huge possibilities of research and technology applications for data processing and communication. Focus has also been laid upon novel communication entity design and application. In this regard a great opportunity for engineering counter measures in the form of optimized antenna design and data telemetry arises.

\section{References}

1. Furfaro T, Alves J (2014) An application of distributed long baseline node ranging in an underwater network. In IEEE OES, UCOMMS.

2. Alves J, Petroccia R, Potter JR (2014) MPR: Multi Point Relay protocol for underwater acoustic networks. WUW Net, Rome, Italy.

3. Caiti A, Feisberto P, Husoy T, Jesus S, Karaasalo I, et al. (2011) Uan underwater acoustic network. In OCEANS IEEE.

4. Proakis J, Rice J, Sozer E, Stojanovic M (2003) Shallow water acoustic networks. In: Proakis JG (Ed.) Encyclopedia of Telecommunications. John Wiley and sons, USA.

5. Freitag L, Stojanovic M (2002) Acoustic Communications for regional underwater observatories. Proceedings of Oceanology International. London, UK.

6. Capitovic J (1990) Performance limitations in underwater acoustic telemetry. IEEE Journal of Ocean Engineering, 15(3): 205-216.

7. Sankarasubramaniam Y, Akan OB, Akyildiz IF (2003) ESRT: event to sink reliable transport for wireless sensor networks. Annapolis, Maryland, USA.

Your next submission with Juniper Publishers
will reach you the below assets
- Quality Editorial service
- Swift Peer Review
- Reprints availability
- E-prints Service
- Manuscript Podcast for convenient understanding
- Global attainment for your research
- Manuscript accessibility in different formats
( Pdf, E-pub, Full Text, Audio)
- Unceasing customer service
Track the below URL for one-step submission
https://juniperpublishers.com/online-submission.php

